\title{
Experimental Study on Wind Erosion of Concrete Building Surface in Wind-Sand Environment
}

\author{
Ying Jia ${ }^{1,2}$, YuFei Pei ${ }^{1, *}$ and ZhiWei Xie ${ }^{1}$ \\ ${ }^{1}$ School of Civil and Architectural Engineering, Beijing Jiaotong University, Beijing 100044, China; $19121091 @$ bjtu.edu.cn (Y.P.); \\ 20121129@bjtu.edu.cn (Z.X.) \\ ${ }^{2}$ Professor, School of Civil Engineering, Beijing Jiaotong University, Beijing 100044, China
}

\begin{abstract}
In this paper, the effects of different wind-sand attack angle, wind speed, action time, concrete strength, sand particle size, and sand content on the surface wind erosion of concrete structures are experimentally studied. Wind erosion rate and strength loss rate are defined as the indexes to measure the degree of wind erosion of concrete. According to the similarity theory, the actual situation is deduced based on the wind erosion test, and the wind erosion time corresponding to the wind speed, the action time of wind sand, and the simulation test in the case of sand content is obtained. it makes the experimental study of wind erosion on concrete buildings to have more practical significance.
\end{abstract}

\section{Introduction}

The research on wind-sand flow began roughly from the middle of the 19th century. At present, the research on wind-sand flow tends to be more systematic, and has been extended to the impact on agriculture, animal husbandry, transportation, construction, and other fields. At present, the research on erosion wear of concrete is mainly focused on the erosion wear of hydraulic concrete caused by sandladen flow [1-4], while the research on wind erosion of concrete is less. There are wind tunnel tests, simulation tests and other methods to study the wind erosion of concrete. The simulation test is a common method to study the wind erosion of concrete in the wind-sand environment, which can simply and efficiently simulate the wind erosion of concrete in the wind-sand flow environment.

In this paper, according to the actual environment of the wind-sand area where the concrete structure is located, the simulation test device of concrete under the action of wind-sand is made, and the test is carried out by using the air-sand-carrying injection method to study the effects of different wind-sand attack angle, wind speed, action time, concrete strength, sand particle size and sand content on the wind erosion of concrete. At the same time, the wind erosion time under the corresponding working conditions is obtained by deducing the actual situation according to the similarity theory.

\section{Experimental study on Wind erosion of concrete in Wind-blown Sand Environment}

In this paper, wind erosion rate and strength loss rate are defined to evaluate the degree of wind erosion of concrete specimens. Wind erosion rate is defined as mass loss per unit area:

$$
\zeta=\frac{\triangle m}{A}
$$

Where: $\zeta$-wind erosion rate, unit is $\mathrm{g} / \mathrm{cm}^{2}$;

$\triangle m$ - quality of the specimen is poor before and after the aeolian action, that is, the quality loss, the unit is $\mathrm{g}$;

A-windward surface area, the unit is $\mathrm{cm}^{2}$.

The strength loss rate is defined as the ratio of the strength difference before and after wind-sand action to the initial strength:

$$
\mu=\frac{p_{0}-p}{p_{0}}
$$

Where: $\mu-$ strength loss rate;

$$
p_{0} \text {-strength of concrete specimen }
$$

before action, unit is $\mathrm{MPa}$;

$p$ - strength of concrete specimen after action, unit is $\mathrm{MPa}$.

\subsection{Wind erosion test under the change of wind- sand angle of attack}

The angle of attack of attack is defined as the angle between the surface of the specimen and the trajectory of incident sand particles. The test results are shown in the 
following figure. Figure 1 shows the curve of the relationship between the wind erosion rate and the angle of attack of wind and sand, and figure 2 shows the curve

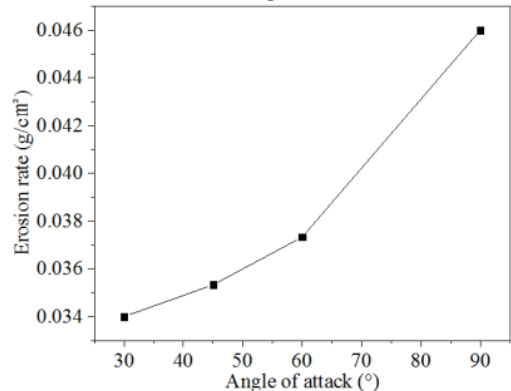

Figure 1. Relationship between erosion rate and angle of attack.

It can be seen from figure 1 that the wind erosion rate of concrete increases significantly with the increase of the attack angle. As it can be seen from figure 2 the strength loss rate increases with the increase of the wind sand angle of attack. The analysis of the reason: the normal stress of the wind-sand load acting on the concrete surface at the low angle is small, and with the increase of the angle, the normal stress component of the wind-sand load increases gradually, so the wind erosion rate increases.

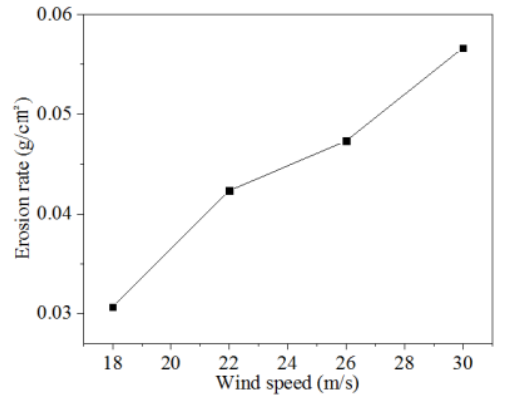

Figure 3. Relationship between erosion rate and wind speed.

It can be seen from figure 3 that the wind erosion rate of concrete specimens increases with the increase of wind speed. It can be seen from figure 4 that when the wind speed increases, the strength loss rate of concrete specimen increases. The reason is that when the wind speed is small, the degree of wind erosion of the concrete specimen is small and has little effect on the strength, but when the wind speed increases, the kinetic energy of the sand increases, and when the concrete specimen is impacted, the damage degree of the sand to the surface of the specimen also increases.

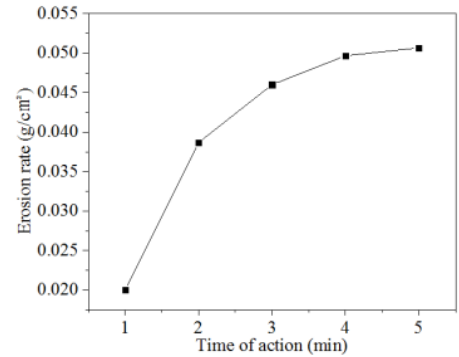

Figure 5. Relationship between erosion rate and action time. of the relationship between the rate of strength loss and the angle of attack.

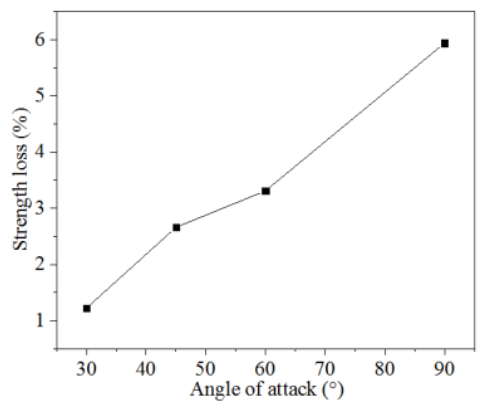

Figure 2. Relationship between strength loss and angle of attack.

\subsection{Wind erosion test under the change of wind speed}

Figure 3 shows the curve of the relationship between the wind erosion rate and wind speed, and figure 4 shows the curve of the relationship between the strength loss rate and wind speed.

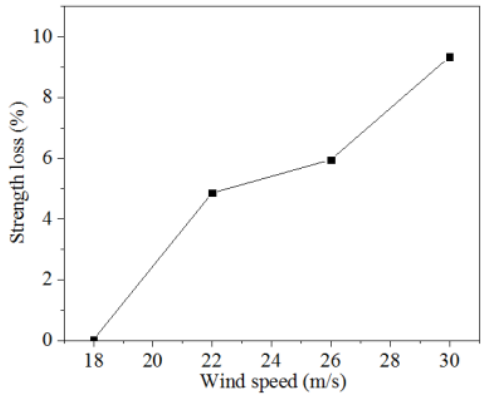

Figure 4. Relationship between strength loss and wind speed.

\subsection{Wind erosion test with different action time of wind-sand}

Figure 5 shows the relationship curve of wind erosion rate with wind-sand action time, and figure 6 shows the relationship curve of strength loss rate with wind-sand action time.

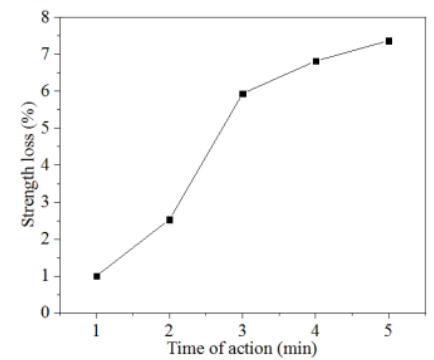

Figure 6. Relationship between strength loss and action time. 
As can be seen from figure 5, with the increase of wind-sand action time, the wind erosion rate of concrete increases, but the increasing trend gradually slows down. The main reason is that the surface of the concrete is mainly composed of cement mortar, its strength and hardness are small, and it is easy to fall off under the action of wind-sand in the early stage, while with the shedding of cement mortar on the surface, the internal coarse aggregate of concrete is exposed gradually. The strength and hardness of coarse aggregate are larger and not easy to fall off, so the increasing trend of wind erosion rate slows down. As it can be seen from figure 6 the strength loss of concrete increases with the increase of wind-sand action time. In the early stage of wind-sand

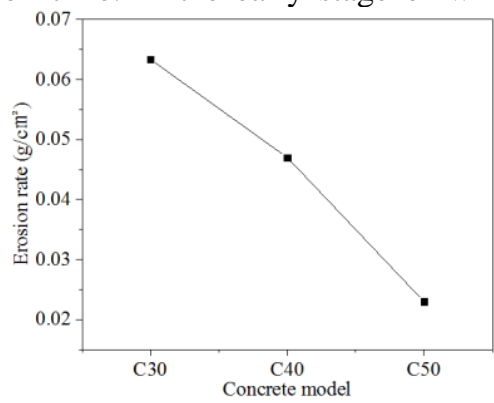

Figure 7. Relationship between erosion rate and concrete strength.

As can be seen from figure 7, the wind erosion rate of concrete decreased from $0.063 \mathrm{~g} / \mathrm{cm}^{2}$ to $0.023 \mathrm{~g} / \mathrm{cm}^{2}$; from figure 8 , the strength loss rate decreased from $7.39 \%$ to $5.51 \%$. The analysis and test results showed that, in a certain range, the ability of high-strength concrete to resist wind erosion is stronger than that of low-strength concrete; with the improvement of concrete strength grade, the strength loss of concrete specimens decreases after wind erosion. The reason is that the water-cement of high strength concrete is relatively small, the combination of cement mortar on the surface of the concrete specimen and

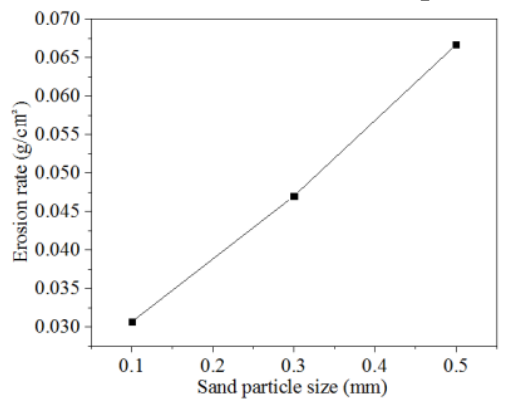

Figure 9. Relationship between erosion rate and sand particle size.

It can be seen from figure 9 that the wind erosion rate of concrete specimens increases significantly with the increase of sand particle size. Also, experiments on the mixed gradation of sand with $50 \% \quad 0.1 \mathrm{~mm}$ and $50 \%$ $0.3 \mathrm{~mm}$ sand were carried out, and the wind erosion rate was $0.039 \mathrm{~g} / \mathrm{cm}^{2}$. Based on the comprehensive analysis of the above results, the reason for the above results is that at the same wind speed, the larger sand particles have greater kinetic energy, and the energy carried by the sand particles is the only source of energy needed to remove the surface action, the strength loss is not obvious, the reason is that cement mortar mainly plays a cementing role and has little effect on the strength; with the wear of coarse aggregate in the later stage, the strength loss increases.

\subsection{Wind erosion test with different concrete strength}

Figure 7 shows the curve of the relationship between the wind erosion rate and the strength grade of concrete, and figure 8 shows the curve of the relationship between strength loss rate and the strength grade of concrete.

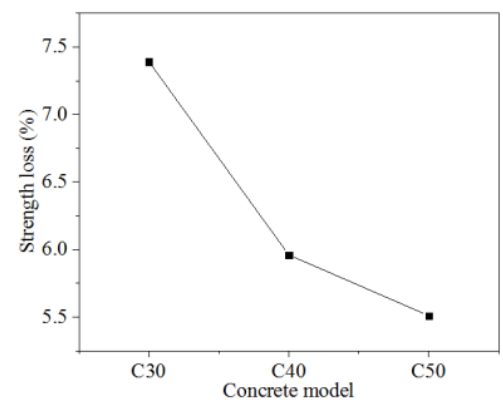

Figure 8. Relationship between strength loss and concrete strength

internal aggregate is relatively dense, and the degree of wind erosion is small and not easy to fall off when subjected to the action of wind and sand.

\subsection{Wind erosion test under the change of sand particle size}

Figure 9 shows the relationship between wind erosion rate and sand particle size, and figure 10 shows the relationship between strength loss rate and sand particle size.

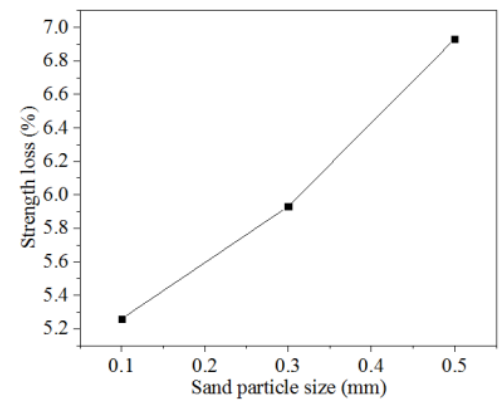

Figure 10. Relationship between strength loss and sand particle size.

materials of the specimen. As a result, the wind erosion rate and strength loss of concrete specimens are increased.

\subsection{Wind erosion test with the change of sediment content}

Figure 11 shows the relationship between erosion rate and sand content, and figure 12 shows the relationship between strength loss rate and sand content. 


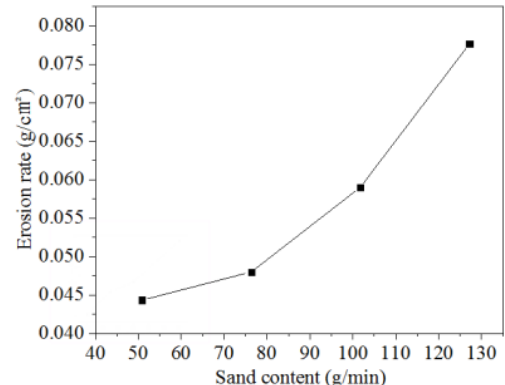

Figure 11. Relationship between erosion rate and sand content.

It can be seen from figure 11 that the wind erosion rate of concrete specimens increases with the increase of sand content. Similarly, as can be seen from figure 12, the strength loss rate increases with the increase of sediment content. When the sand content is $50.88 \mathrm{~g} / \mathrm{min}$, the strength loss rate is $5.57 \%$. When the sand content increases to $127.2 \mathrm{~g} / \mathrm{min}$, the strength loss rate increases to $7.23 \%$. The reason is that under the condition of certain parameters such as wind angle of attack, wind speed and sand particle size, the greater the sand content is, the more sand impinges on the surface of concrete specimen per unit time, and the more impact times the specimen is subjected to. As a result, the wind erosion rate and strength loss of concrete specimens increase.

$$
C_{\mathrm{W}}=\frac{W_{\mathrm{m}}}{W_{\mathrm{p}}}=\frac{\frac{1}{2} m_{\mathrm{m}} v_{\mathrm{m}}^{2}}{\frac{1}{2} m_{\mathrm{p}} v_{\mathrm{p}}^{2}}
$$

Where, $W_{\mathrm{p}} 、 m_{\mathrm{p}} 、 v_{\mathrm{p}}$ are the kinetic energy, mass, and velocity of the prototype; $W_{\mathrm{m}}, m_{\mathrm{m}}, v_{\mathrm{m}}$ are the kinetic energy, mass, and velocity of the simulation test.

According to meteorological statistics, when the wind speed of three or more measuring stations reaches $20 \mathrm{~m} / \mathrm{s}$, the regional sand load reaches $7.8 \mathrm{mg} / \mathrm{m}^{2} \cdot \mathrm{s}$, and the duration of high wind speed is within $30 \mathrm{~min}$, it is the sign of severe sandstorm on a large scale [5]. When the

$$
C_{\mathrm{W}}=\frac{W_{\mathrm{m}}}{W_{\mathrm{p}}}=\frac{\frac{1}{2} m_{\mathrm{m}} v_{\mathrm{m}}{ }^{2}}{\frac{1}{2} m_{\mathrm{p}} v_{\mathrm{p}}{ }^{2}}=\frac{76.32 \times 18^{2}}{46.8 \times 20^{2}}=1.32
$$

When the actual frequency of sandstorms is 15 times a year, the wind-blown sand action time of the simulation test is $3 \mathrm{~min}$, and the actual action time of 15 sandstorms

$$
\frac{W_{\mathrm{m}}^{15}}{W_{\mathrm{p}}^{15}}=\frac{3}{450} C_{\mathrm{W}}=0.0087
$$

Therefore, the wind erosion damage effect of a $3 \mathrm{~min}$ simulation test on concrete is equivalent to that of concrete structures subjected to wind erosion for 3 days when sandstorms occur 15 times a year.

Based on the time relationship between the test results and the actual situation calculated by the above kinetic is $450 \mathrm{~min}$, the kinetic energy similarity ratio between the simulation test and the prototype is:

energy similarity ratio, the actual wind erosion time deduced by the simulation test under different wind speed, sand action time, and sediment concentration is obtained, as shown in figures 13, 14 and 15 . 


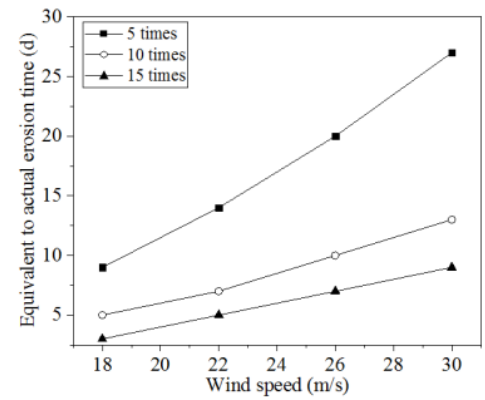

Figure 13. Correspondence between the wind speed test and the actual situation.

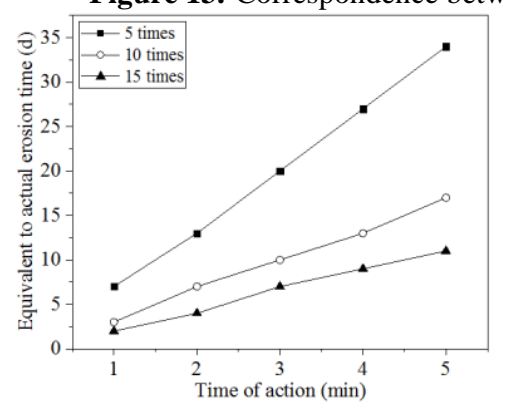

Figure 14. Correspondence between the action time test and the actual situation.

\section{Conclusions}

In this paper, the simulation test of wind erosion on the surface of a concrete building under wind-sand environment is carried out, and the similarity theory is applied to study the similarity between the simulation test and the actual situation based on wind speed, wind-sand action time and sand content. The results are as follows: under the action of wind and sand, the wind erosion rate and strength loss of concrete increase significantly with the increase of attack angle, wind speed, action time, particle size, and sand content. In a certain range, the resistance to wind erosion of high-strength grade concrete is stronger than that of low strength grade concrete, and the strength loss is also reduced.

The research conclusions can provide a reference for the maintenance of existing concrete buildings in windsand areas, as well as for the construction of roads, bridges, and railways in wind-sand areas.

\section{Acknowledgments}

Thanks to the project [51778051] of the National Natural Science Foundation of China for supporting this research.

\section{References}

1. ACI Committee 2101955 Erosion Resistance of Concrete in Hydraulic Structure J. Proc.52(3) pp 259271

2. Price W H 1947 Erosion of Concrete by Cavitation and Solids in Flowing Water U.S. Bureau of Reclamation Laboratory Report (USA: U.S.) p 342

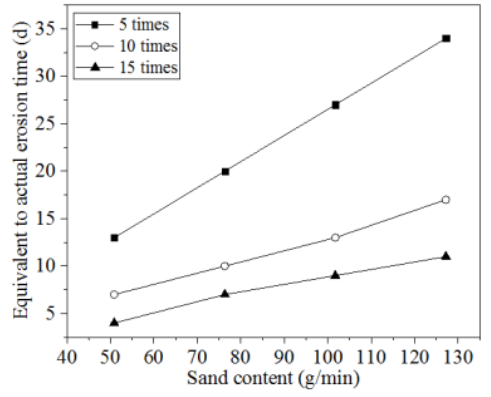

Figure 15. Correspondence between the sand content test and the actual situation.

3. Liu Y W, Yen T, Hsu TH 2006 Abrasion Erosion of Concrete by Water-borne Sand J. Cem. Concr. Res. 36 pp 1814-20

4. Yin Y G, Hu X G, Cui Demi 2001 Research on Impact Wear Behavior and Mechanism of Hydraulic Concrete J. Hydroelectric. Eng. 4 pp 57-64

5. Feng Y J 2015 Research on Mechanism and Evaluation of Erosion Damage of Concrete in WindSand Environment (Hohhot: Inner Mongolia University of Technology) p 45 